\title{
Association between Work Experience and Work-Related Musculoskeletal Disorders among the Clinical and Teaching Physiotherapists of Gujarat, India - An Observational Study
}

\author{
Ramanandi $\mathbf{V}^{1}$
}

1SPB Physiotherapy College, Surat, Gujarat, India

\section{ABSTRACT}

Introduction: Work-related musculoskeletal disorders (MSDs) are present universally where physiotherapists are found to be at higher risk of being affected due to the postures attained at work. This can lead to excessive exertion associated with significant discomfort and pain in loading joints. In addition to these, the anatomical, physiological and physical characteristics of males and females are disparate so gender-based differences may also affect. However, a paucity of data for correlating the years of experience with MSDs was found in Gujarat. Hence, the present study was undertaken to investigate the association between the prevalence of MSDs with an increase in work experience among the physiotherapists of Gujarat.

Methods: This was an online cross-sectional survey study where 322 physiotherapists were included after gaining informed electronic consent. Prevalence rates were found by employing a standardized Nordic Musculoskeletal Questionnaire (NMQ) and non - parametric tests were used for data analysis.

Results: The majority of the physiotherapists reported complaints of MSDs in the lower back (41.30\%) and neck $(37.58 \%)$ regions. It was also observed that females (68.63\%) have more prevalence compared to males $(61.19 \%)$. Conclusion: It is inferred that the chances of being affected by MSDs do not increase with years of work experience. Moreover, female physiotherapists are more prone to MSDs. Thus, early identification and interventions through ergonomic advice and physiotherapy can prove to be very effective in declining the rate of MSDs to a notable extent.

Key words: Musculoskeletal disorders, Occupational Health, Occupational injury, Physical therapists, Prevalence, Risk factors.

\section{Introduction}

n recent years, work-related musculoskeletal disorders (MSD) have become very familiar worldwide. ${ }^{1}$ "Work-Related Musculoskeletal Disorders" can be described as inflammatory and degenerative diseases and disorders that result in pain and functional impairment. ${ }^{2}$ According to World Health Organization

DOI: https://doi.org/10.3126/ijosh.v11i1.33372

Date of submission: 12.12 .2020

Date of acceptance: 23.03 .2021

\section{Corresponding Author}

Vivek Harsukhbhai Ramanandi

MPT (Neuro), PhD Scholar, Gujarat University.

Assistant Professor,

SPB Physiotherapy College, Surat. Gujarat, India

Tel: +917878585656

E-mail: vivekramanandi@gmail.com

ORCID ID: 0000-0001-8624-7220
(WHO), it is defined as any health problem of the locomotor apparatus including all forms of reversible, light, transitory disorder or irreversible, disabling injuries of the nerves, tendons, muscles, bones, joints, ligaments, spinal disc, cartilage and blood vessels..$^{3,4}$ They are related to repetitive and demanding working conditions which continue to represent one of the biggest problems in industrialized countries. ${ }^{5}$ They are the common cause of work-related disability in a varied range of professions and according to studies physiotherapists typically report a higher incidence, more frequent and worse MSD defects than any other high-risk medical professionals. ${ }^{6-8}$ 
Physiotherapists in routine training and practice environments are challenged with many occupational health barriers. They are prone to physical and psychological stressors which are aggravated more by their work environment. ${ }^{9}$ Multifactorial mechanisms are responsible for work-related musculoskeletal pain and disorders. These mechanisms may include numerous risk factors including the need for the prolonged application of manual strength; prolonged awkward static postures (stooping, slouching, ducking); poor positioning; repetitive movements of neck \& shoulder flexion/abduction; the repetitive excessive strain on the spine; inadequate work breaks; coping with patient's anxieties - mental stress; genetic predisposition; physical conditioning; age; time pressure; high demand and poor social support.5, 8-10

The findings regarding the psychosocial work environment-related issues are less conclusive leading to the consideration of the additional fact that the anatomical, physiological and physical characteristics of males and females working as physiotherapists are disparate, so gender bias may become an instinct. The studies have already depicted that the postures attained at work, which requires more than 50 percent of the body's muscles to contract to hold the body motionless while resisting gravity, is one of the most devastating physical factors. As the age and years of clinical work since the graduation increase, the static forces resulting from such postures can become much more taxing than moving (dynamic) forces and can manifest distinctly in MSD pains. ${ }^{11,12}$

In one of the previous studies, it was found that the lifetime prevalence of work-related MSDs was $91 \%$, whereas one in six physiotherapists moved within or left the profession due to work-related MSDs. ${ }^{13}$ In an Indian study, the results suggested the highest prevalence of MSDs (42.01\%) among physiotherapists between 22 and 25 years of age where the majority of physiotherapists (35.48\%) first experienced their workrelated MSDs within five years of graduation. ${ }^{14,15}$

Several studies assessing the prevalence of workrelated MSDs and the effects of specific anatomic site, gender, posture etc. on physiotherapists have been found in India ${ }^{14-16}$ but no studies finding the relationship between MSDs and work experience have been done. However, the issue of the rising paucity of literature regarding the association of an increase in work experience with MSDs has been reported previously in India. Therefore, this study aimed to investigate the association between the prevalence rate of MSDs with work experience among the physiotherapists working in clinical and teaching professions from Gujarat state in India.

\section{Methods}

This internet-based online survey type study was conducted from $1^{\text {st }}$ October 2020 to $10^{\text {th }}$ October 2020 through the use of Google form circulated through e-mails, social media and personal messages to invite the clinicians and teachers from the physiotherapy profession from all over Gujarat state. Out of 351 total responses which were received online, 322 $(91.7 \%)$ data of the physiotherapists were considered for analysis due to incomplete or unclear data of the remaining responses.

Subjects who were qualified physiotherapists having at least an undergraduate professional degree were included after agreeing to participate by checking in the electronic participation consent. Each subject was required to fill up an assessment form consisting of questions regarding their basic demographic details; professional details such as job/position; experience, weekly working hours and health information using standardized Nordic Musculoskeletal Questionnaire (NMQ) and submit it online.

Standardized NMQ is one of the most frequently used symptom questionnaire, designed for all musculoskeletal disorders. It was used to assess the nature and severity of self-reported musculoskeletal complaints concerning nine body areas such as the neck, shoulder, elbows, wrists/hands, upper back, lower back, hips, knees and ankles/feet. The occurrences of these symptoms over the past seven days (weekly prevalence) and the past 12 months (annual prevalence) were captured. The tool was not developed for clinical diagnosis and can be used as a questionnaire or as a structured interview. ${ }^{17,18}$ For the 27 dichotomous variables, the kappa values ranged between 0.57 and 1.00 was used in the reliability assessment. The kappa value for criterion validity obtained for the agreement between participants' clinical records and questionnaires was $0.76 .{ }^{19}$

Data were collected and analyzed for association between work experience and prevalence rate of MSDs; a further association between the age, gender, height, weight, with the prevalence of MSDs was also found. The comparison was also done among genders to note any difference if present. 
Basic descriptive analysis and graph generation was done using Microsoft Excel for Windows, whereas ChiSquare test of association for finding an association between work experience, gender, height and weight with prevalence rate and comparison between genders for MSDs prevalence was done using Statistical Package for the Social Sciences (SPSS) 20 for Windows.

\section{Results}

Out of all participants, the majority were from younger age groups i.e. $25-30$ years $(58.07 \%)$ and $31-35$ years (27.02\%). Among them 255 (79.19\%) were female and $67(20.81 \%)$ were male.

The mean height of the respondents was $159.97 \mathrm{~cm}$ $\pm 17.12 \mathrm{~cm}$ (Mean $\pm \mathrm{SD}$ ) and weight was $62.56 \mathrm{~kg} \pm$ $12.29 \mathrm{~kg}$ (Mean \pm SD) among the total study population.

Table-1 shows the general prevalence of MSDs among both clinicians as well as teaching physiotherapists. As it can be seen in the graph-1, region-wise general prevalence was found to be neck- $37.58 \%$, shoulder$31.99 \%$, elbow- $9.63 \%$, wrist \& hand- $16.77 \%$, upper back- $33.85 \%$, lower back- $41.30 \%$, hip- $13.66 \%$, knee$21.12 \%$ and ankle \& feet-21.12\%.

Out of the total of 322 physiotherapists, a total of $67.08 \%(n=216)$ responded 'yes' in response to the question regarding trouble in any one or more regions during the past 12 months. Total $61.19 \%(n=41)$ male and $68.63 \%(n=175)$ physiotherapists responded 'yes' to having trouble during the past 12 months indicating MSDs.

Table-2 and graph-2 depicted the distribution of physiotherapists having MSDs based upon their years of experience. It showed that the highest number of MSDs (i.e. $87.50 \%$ ) was present in the physiotherapists with $>20$ years of experience whereas the lowest number of MSDs was present in the fresher physiotherapists having 0-1 year of experience.

Table-3 showed the values of the Chi-Square test of association for working experience (years), gender, age (years), height $(\mathrm{cm})$ and weight $(\mathrm{kg})$ with the prevalence of MSDs in physiotherapists. The results showed that the $p$-values were statistically not significant at $\alpha=$ 0.05 levels indicating that no variable is significantly associated with the prevalence of MSDs.

Table 1: Prevalence of Musculoskeletal Disorders among Physiotherapists $(n=322)$

\begin{tabular}{|c|c|c|c|c|c|c|c|}
\hline \multirow[t]{2}{*}{ Region } & \multirow[t]{2}{*}{ Response } & \multicolumn{2}{|c|}{$\begin{array}{l}\text { Prevalence } \\
\qquad(n=322)\end{array}$} & \multicolumn{2}{|c|}{$\begin{array}{l}\text { Prevalence among } \\
\text { Male }(n=67)\end{array}$} & \multicolumn{2}{|c|}{$\begin{array}{c}\text { Prevalence among } \\
\text { Female }(n=255)\end{array}$} \\
\hline & & $\%$ & $\mathbf{n}$ & $\%$ & $\mathbf{n}$ & $\%$ & $\mathbf{n}$ \\
\hline Neck & Yes & 37.58 & 121 & 31.34 & 21 & 39.22 & 100 \\
\hline \multirow{3}{*}{ Shoulder } & Yes, Both & 12.11 & 39 & 11.94 & 8 & 12.16 & 31 \\
\hline & Yes, Right Side & 10.25 & 33 & 8.96 & 6 & 10.59 & 27 \\
\hline & Yes, Left Side & 9.63 & 31 & 16.42 & 11 & 7.84 & 20 \\
\hline \multirow{3}{*}{ Elbow } & Yes, Both & 1.86 & 6 & 2.99 & 2 & 1.57 & 4 \\
\hline & Yes, Right Side & 5.28 & 17 & 5.97 & 4 & 5.10 & 13 \\
\hline & Yes, Left Side & 2.48 & 8 & 1.49 & 1 & 2.75 & 7 \\
\hline \multirow{3}{*}{ Wrist \& Hand } & Yes, Both & 6.52 & 21 & 8.96 & 6 & 5.88 & 15 \\
\hline & Yes, Right Side & 6.52 & 21 & 7.46 & 5 & 6.27 & 16 \\
\hline & Yes, Left Side & 3.73 & 12 & 4.48 & 3 & 3.53 & 9 \\
\hline Upper Back & Yes & 33.85 & 109 & 25.37 & 17 & 36.08 & 92 \\
\hline Lower Back & Yes & 41.30 & 133 & 40.30 & 27 & 41.57 & 106 \\
\hline \multirow{3}{*}{ Hip } & Yes, Both & 8.07 & 26 & 8.96 & 6 & 7.84 & 20 \\
\hline & Yes, Right Side & 3.73 & 12 & 5.97 & 4 & 3.14 & 8 \\
\hline & Yes, Left Side & 1.86 & 6 & 2.99 & 2 & 1.57 & 4 \\
\hline \multirow{3}{*}{ Knee } & Yes, Both & 11.18 & 36 & 7.46 & 5 & 12.16 & 31 \\
\hline & Yes, Right Side & 5.59 & 18 & 7.46 & 5 & 5.10 & 13 \\
\hline & Yes, Left Side & 4.35 & 14 & 2.99 & 2 & 4.71 & 12 \\
\hline \multirow{3}{*}{ Ankle \& Feet } & Yes, Both & 10.56 & 34 & 8.96 & 6 & 10.98 & 28 \\
\hline & Yes, Right Side & 6.52 & 21 & 5.97 & 4 & 6.67 & 17 \\
\hline & Yes, Left Side & 4.04 & 13 & 2.99 & 2 & 4.31 & 11 \\
\hline
\end{tabular}


Table 2: Experience wise Prevalence of MSDs $(n=322)$

\begin{tabular}{cccc}
\hline Experience & Frequency $(\mathbf{n})$ & MSD $(\mathbf{n})$ & MSD (\%) \\
\hline 0-1 years & 101 & 62 & 61.39 \\
$1-3$ years & 88 & 59 & 67.05 \\
3-5 years & 31 & 25 & 80.65 \\
$5-10$ years & 79 & 52 & 65.82 \\
$10-20$ years & 15 & 11 & 73.33 \\
$>$ 20 years & 8 & 7 & 87.50 \\
\hline Total & $\mathbf{3 2 2}$ & $\mathbf{2 1 6}$ & \\
\hline
\end{tabular}

Table 3: Chi-Square Values for Association between the Variables $(\alpha=0.05)$

\begin{tabular}{ccccc}
\hline Variables & Chi-Square Value & Degree of Freedom & $\begin{array}{c}\text { P - value } \\
\text { (2-sided) }\end{array}$ & $\begin{array}{c}\text { Statistical } \\
\text { Significance }\end{array}$ \\
\cline { 1 - 3 } Working Experience & 5.90 & 5 & .316 & .758 \\
Gender & 0.10 & 1 & .225 & Not Significant \\
\cline { 1 - 3 } Age Group (Years) & 5.67 & 4 & .409 & .132 \\
\hline Height $(\mathrm{cm})$ & 37.30 & 36 & 42 & \\
\hline
\end{tabular}

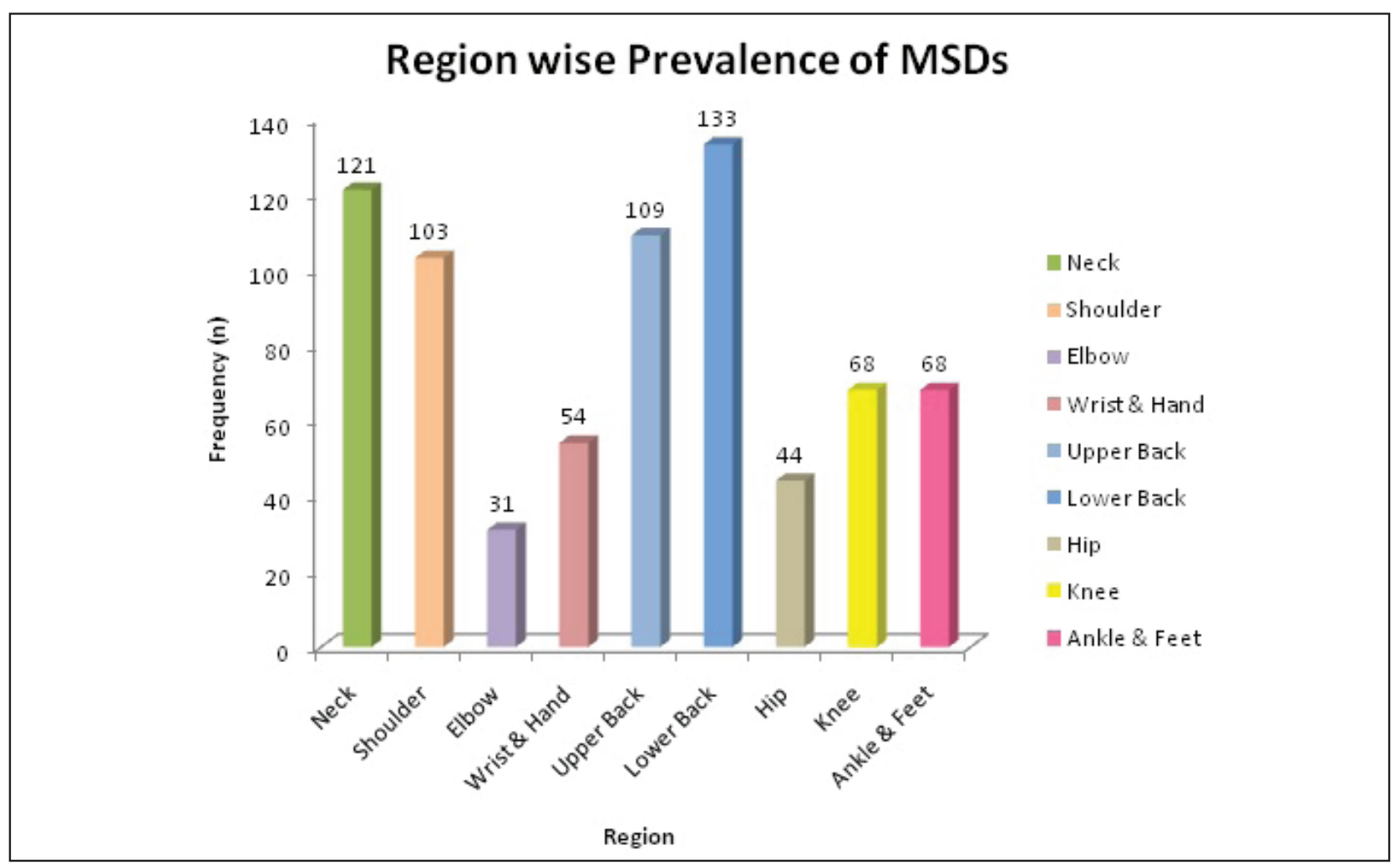

Figure 1: Region wise Prevalence of MSDs 


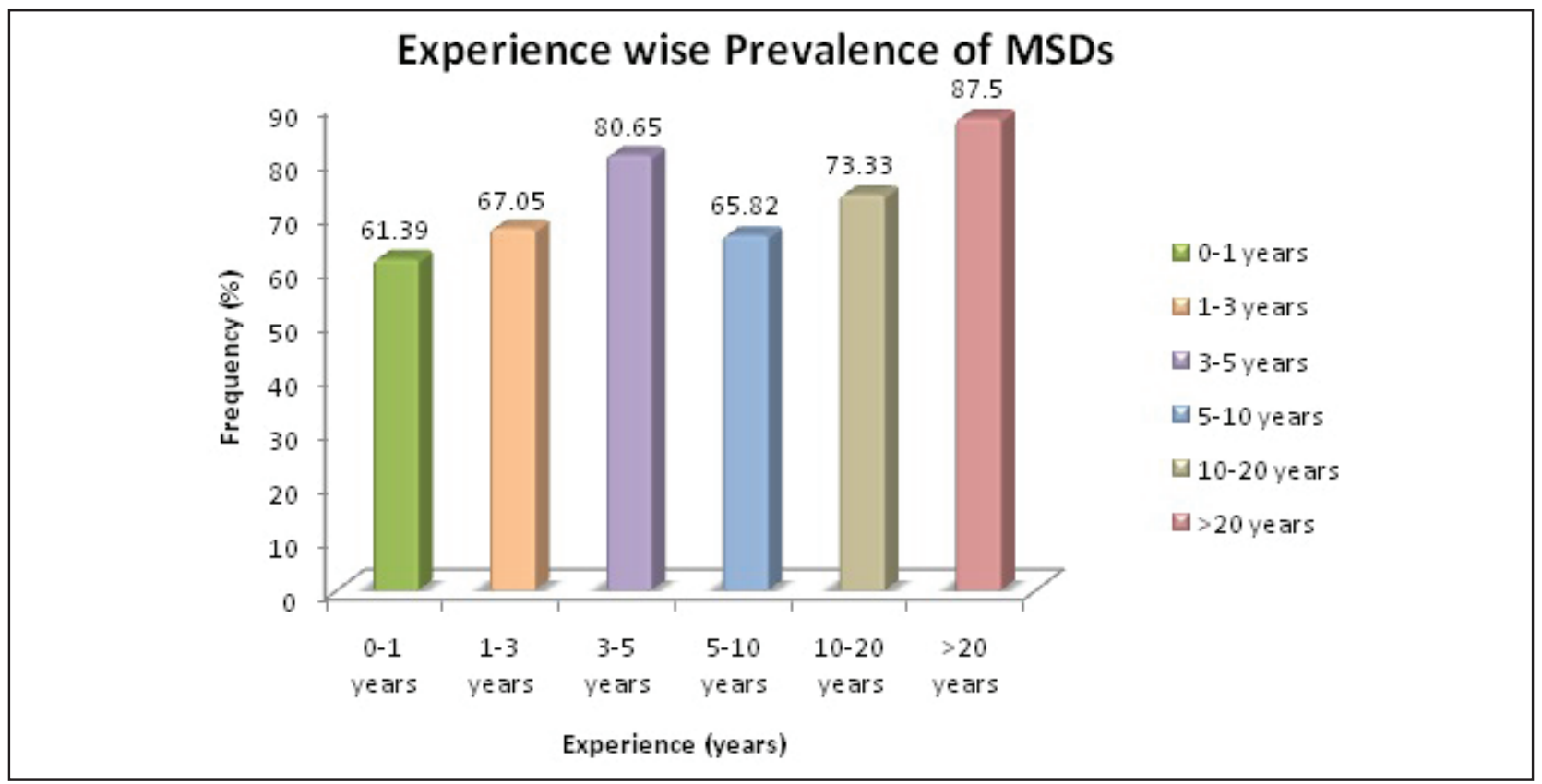

Figure 1: Region wise Prevalence of MSDs

\section{Discussion}

The results of the present study reveal that years of work experience of a physiotherapist do not have any significant relation with musculoskeletal system disorders, thus the common assumption about their correlation is not supported by the findings of this study.

Globally, the prevalence of occupational healthrelated problems is a concern among physiotherapy practitioners and work MSD is one of the most prevalent causes of having a multifactorial origin. Many studies have found that work-related MSDs are on the increase, despite new and innovative equipment being developed and used to make the clinical practice of healthcare practitioners easy. ${ }^{10,20-22}$ As previous studies have shown that physiotherapists experience common work-related MSD symptoms with a high prevalence rate, it was thought to be important to find its association with the years of work experience among the dentists.

It is accepted that the cumulative effect of chronic fatigue, discomfort, and pain due to poor work habits such as poor posture can cause musculoskeletal pain when working for a long time even if the soft tissues are not structurally altered developing the MSD symptoms. ${ }^{6,9,22}$ Additionally, as physiotherapists work on an average for 45-60 minutes with a patient during a single session, those with more work experience become prone to eventually experience musculoskeletal problems. ${ }^{15}$
The main finding of the present study suggested that the years of experience do not correlate with the prevalence of work-related MSDs. Similar findings were seen in a study from India, where, MSDs were found to be more prevalent on the younger physiotherapists with lesser experience. This can be because younger physiotherapists work usually for more hours and work more vigorously as they are more concerned to navigate their career on the right path. In the present study, the number of respondents having $<5$ years of experience was more $(n=220)$ as compared to $>5$ years experienced physiotherapists which may also affect the representation for the same group. Few other studies have also shown that MSD pain was negatively correlated with experience years for dentists. ${ }^{23,24}$ One research explained this to be associated with the fact that clinicians with a lot of experience learnt to adapt their work posture and avoid MSDs, or that the physiotherapists with MSDs might move within or leave physiotherapy as a profession. ${ }^{13,25}$

The experience wise prevalence of MSDs was found to be high, i.e. $87.5 \%$ and $73.33 \%$, in the groups of physiotherapists having $>20$ years and $10-20$ years of experience respectively. This can be due to less number of subjects $(n=23)$ in both the groups and as the age of these physiotherapists are supposed to be more, age-associated MSDs may have affected their responses.

Region-wise prevalence of MSDs showed that the 
lower back $(n=133)$ and neck $(n=121)$ were the most affected regions for the physiotherapists. The upper back $(n=109)$ and the shoulder $(n=103)$ were the most affected regions following them. These results were similar to the findings of various studies done in past in India and abroad. ${ }^{26-28}$

Furthermore, the results of this study that the female has a higher prevalence of MSDs than male, is in consistency with the previous studies which encounters same results and suggested higher incidence rate of developing MSDs when compare to their counterparts. ${ }^{15,16}$ This can be accounted for by the difference in their anatomical and physiological body built such as higher body weight, smaller height and differences in muscle strength \& composition which makes females more prone for MSDs than males. However, this finding contradicts with previous studies, where one study reported that there were no significant differences among male and female. ${ }^{27}$

This study shows the need to practice preventive measures for avoidance of work-related MSDs during professional practise for physiotherapists. In accordance to decrease the prevalence of MSDs and increase productivity, the role of ergonomics, healthy work environment, prevention of injury, counseling, etc., need to be emphasized during the training of physiotherapist so that they can use their body force efficiently and effectively without inadvertently loading any specific part of the body. ${ }^{29}$ In addition to this, as the number of female physiotherapists is more, they are likely to benefit from additional improvements in the work environment, targeted prevention and intervention aimed at reducing these risks. ${ }^{21}$

As for any research, this study also presented its limitations. As the data were collected using an online survey technique, the more experienced physiotherapists from the higher age group may not have participated due to lesser familiarity with the use of internet-based surveys. That led to fewer responses from such higher experience groups which might have affected the findings. It can be overcome by conducting an in-person survey for such physiotherapists using a printed survey form. Further, as the survey included self-reported measure, participant memory could have affected their responses and in turn, affected results. Secondly, this survey would have been more informative if the number of daily patients treated and various areas of practice and techniques used by physiotherapists were collected and their relationship to work-related MSDs was examined.

We suggest more elaborated research including the causes of MSDs; effects of the MSDs on quality of life and work productivity as well as psychological effects of MSDs on the physiotherapist; their coping strategies etc. with a larger sample size should be conducted and other factors should be correlated to generalize the results and conclusions, and thereby formulate some guidelines to prevent or minimize work-related MSDs in physiotherapists in future.

\section{Conclusion}

The present study shows that there is no significant relationship between work experience, gender, age, weight and height with the prevalence rate of MSDs. The MSDs in physiotherapists are mostly affecting the neck and lower back regions followed by the upper back and shoulders. Male physiotherapists are less affected by MSDs as compared to female physiotherapists. Therefore, awareness of ergonomic advice and precautionary activities can be included during training years for physiotherapists to develop healthy working habits and prevent work-related MSDs.

This study investigated unanswered questions about physiotherapists of Gujarat and WMSDs and provided a basis for further work which can be expected to lead to the development of preventive strategies for physiotherapy professionals.

\section{References}

1. Alexopoulos EC, Stathi I-C, Charizani F. Prevalence of musculoskeletal disorders in dentists. BMC musculoskeletal disorders. 2004;5(1):16.

2. Scholey $M$, Hair M. Back pain in physiotherapists involved in back care education. Ergonomics. 1989;32(2):179-90.

3. Bork BE, Cook TM, Rosecrance JC, Engelhardt KA, Thomason M-EJ, Wauford IJ, et al. Work-related musculoskeletal disorders among physical therapists. Physical therapy. 1996;76(8):827-35.

4. Shaik AR, Rao SB, Husain A, D'sa J. Work-related musculoskeletal disorders among dental surgeons: A pilot study. Contemporary clinical dentistry. 2011;2(4):308. 
5. Batham C, Yasobant S. A risk assessment study on work-related musculoskeletal disorders among dentists in Bhopal, India. Indian Journal of Dental Research. 2016;27(3):236.

6. Holder NL, Clark HA, DiBlasio JM, Hughes CL, Scherpf JW, Harding L, et al. Cause, prevalence, and response to occupational musculoskeletal injuries reported by physical therapists and physical therapist assistants. Physical therapy. 1999;79(7):642-52.

7. lqbal Z, Alghadir A. Prevalence of work-related musculoskeletal disorders among physical therapists. Med Pr. 2015;66(4):459-69.

8. Al-Eisa E, Buragadda S, Shaheen A, Ibrahim A, Melam GR. Work related musculoskeletal disorders: causes, prevalence and response among egyptian and saudi physical therapists. Middle-East Journal of Scientific Research. 2012;12(4):523-9.

9. Pejcic N, Petrovic V, Markovic D, Milicic B, Dimitrijevic II, Perunovic N, et al. Assessment of risk factors and preventive measures and their relations to workrelated musculoskeletal pain among dentists. Work. 2017;57(4):573-93.

10. Campo M, Weiser S, Koenig KL, Nordin M. Workrelated musculoskeletal disorders in physical therapists: a prospective cohort study with 1-year follow-up. Physical therapy. 2008;88(5):608-19.

11. Paldhikar S, Bhatkar S, Ghodey S. Incidence and study of occupational factors associated with low back pain in dentists in Pune region India. IOSR Journal of Dental and Medical Sciences. 2012;3(2):08-12.

12. Joshi Medhavi H, Desai Devangi S, Singh Lalli M, Joshi Vaibhavi A. Correlation between Work Experience and Musculoskeletal Disorders among the Dentists of Vadodara, Gujarat, India. 2019;6(12):27-32.

13. Cromie JE, Robertson VJ, Best MO. Work-related musculoskeletal disorders in physical therapists: prevalence, severity, risks, and responses. Physical therapy. 2000;80(4):336-51.

14. Muruganantham B, Nayak B, Dave D, Kotia P. Work-related musculoskeletal disorders among Indian Physiotherapists. Physiotherapy. 2015;101:e1059-e1060.

15. Priyanka M, Retasha S, Niti P. Work Related Musculoskeletal Disorders: A Survey of Physiotherapists in Tricity. International Journal of Physiotherapy. 2015;2(6):1091-6

16. Buddhadev NP. Work-related musculoskeletal disorders: a survey of physiotherapists in Saurashtra region. National journal of medical research. 2012;21(25):179-81.
17. Kuorinka I, Jonsson B, Kilbom A, Vinterberg H, BieringSorensen F, Andersson G, et al. Standardised Nordic questionnaires for the analysis of musculoskeletal symptoms. Applied ergonomics. 1987;18(3):233-7.

18. Crawford JO. The Nordic musculoskeletal questionnaire. Occupational medicine. 2007;57(4):300-1.

19. Legault EP, Cantin V, Descarreaux M. Assessment of musculoskeletal symptoms and their impacts in the adolescent population: adaptation and validation of a questionnaire. BMC pediatrics. 2014;14(1):1-8.

20. Glover W, McGregor A, Sullivan C, Hague J. Work-related musculoskeletal disorders affecting members of the Chartered Society of Physiotherapy. Physiotherapy. 2005;91(3):138-47.

21. Sharan D, Ajeesh P. Injury prevention in physiotherapists-a scientific review. Work. 2012;41(Supplement 1):1855-9.

22. Nkhata LA, Zyaambo C, Nzala S, Siziya S. Workrelated musculoskeletal disorders: Prevalence, contributing factors and coping strategies among physiotherapy personnel in Lusaka, Kitwe and Ndola districts, Zambia. Medical journal of Zambia. 2010;37(4):262-7.

23. Leggat $P$, Smith $D$. Musculoskeletal disorders selfreported by dentists in Queensland, Australia. Australian dental journal. 2006;51(4):324-7.

24. Finsen L, Christensen H, Bakke M. Musculoskeletal disorders among dentists and variation in dental work. Applied ergonomics. 1998;29(2):119-25.

25. Leggat PA, Kedjarune U, Smith DR. Occupational health problems in modern dentistry: a review. Industrial health. 2007;45(5):611-21.

26. Malarvizhi D, Kumar MK, Sivakumar VPR. Prevalence of Work-Related Musculoskeletal Disorders Among Clinical and Teaching Physiotherapists An Observational Study. International Journal of Physiotherapy. 2017;4(2):86-92.

27. Salik Y, Ozcan A. Work-related musculoskeletal disorders: a survey of physical therapists in Izmir-Turkey. BMC musculoskeletal disorders. 2004;5(1):27.

28. Kalyani VR, Wani SK, Rairikar S, Shyam A, Sancheti P. Correlation of physical factors with musculoskeletal pain among physiotherapists. Indian Journal of Pain. 2017;31(1):50-4.

29. Soukup MG, Lonn J, Glomsrod B, Bo K, Larsen S. Exercises and education as secondary prevention for recurrent low back pain. Physiotherapy research international. 2001;6(1):27-39. 